\title{
LUMINESCENCE OF A HIGHLY CHARGED MERCURY-LIKE ION: TELLURIUM(IV)
}

\author{
G. BLASSE, G.I. DIRKSEN and P.A.M. BERDOWSKI \\ Physical Laboratory, State University, P.O. Box 80.000, 3508 TA Utrecht, The Netherlands
}

Received 30 August 1984

The luminescence of $\mathrm{Rb}_{2} \mathrm{TeBr}_{6}$ is reported and interpreted in terms of the $5 s^{2}$ configuration of the $\mathrm{Te} \mathrm{e}^{4+}$ ion.

The luminescence of mercury-like ions is well known and has been studied in detail [1]. Especially the alkali halides doped with mercury-like ions have been investigated thoroughly [2]. These studies are restricted to ions with valencies 1,2 and 3 . Here we wish to report the observation of luminescence from a more highly charged ion, viz. $\mathrm{Te}^{4+}\left(5 \mathrm{~s}^{2}\right)$.

For our investigation we selected the compound $\mathrm{Rb}_{2} \mathrm{TeBr}_{6}$. Recently its crystal structure has been determined down to liquid-helium temperatures [3]. At room temperature the structure is of the $\mathrm{K}_{2} \mathrm{PiCl}_{6}$ type, i.e. the $\mathrm{TeBr}_{6}^{2-}$ octahedra have perfect octahedral symmetry and do not share anions. At $45 \mathrm{~K}$ a phase transition occurs, but the $\mathrm{TeBr}_{6}^{2-}$ group remains undistorted. They only show a ferrorotative displacement with tilt angle $4.7^{\circ}$. This compound seems therefore to be ideal as a model compound for investigation of the luminescence of the $\mathrm{Te}^{4+}$ ion.

Samples were prepared as described in ref. [3]. They were checked by X-ray diffraction. They have a brilliant red colour. The way in which the optical measurements were performed has been described before [4].

Below $200 \mathrm{~K} \mathrm{Rb}_{2} \mathrm{TeBr}_{6}$ shows a strong deep-red luminescence under ultraviolet and visible excitation. The emission spectrum consists of a single band with a maximum at about $680 \mathrm{~nm}$. The emission intensity is temperature independent from liquid-helium temperature to $100 \mathrm{~K}$. The thermal quenching region $\mathrm{ex}$ tends from about 100 to $180 \mathrm{~K}$.

The excitation spectrum of this emission contains three bands, viz. an asymmetric one with a maximum at about $485 \mathrm{~nm}(\mathrm{~A})$, another one at $410 \mathrm{~nm}$ and a broad one at about $350 \mathrm{~nm}$ (C). Their intensities are about equal. This implies a Stokes shift of $0.75 \mathrm{eV}$. The energy difference between the $A$ and $C$ band is about $1.1 \mathrm{eV}$. When this work was finished, we became aware of similar emission spectra at $77 \mathrm{~K}$ for $\mathrm{Cs}_{2} \mathrm{TeCl}_{6}$ and $\mathrm{Cs}_{2} \mathrm{TeBr}_{6}$ (ref. [5]).

All decay curves of the emission were exponential. Fig. 1 shows the temperature dependence of the decay time of the luminescence of $\mathrm{Rb}_{2} \mathrm{TeBr}_{6}$. Between 10 and $20 \mathrm{~K}$ there is a drop in decay time from the millisecond to the microsecond region. Note that the luminescence intensity is constant in this temperature range. This shows that the decay times have to be analysed with a three-level scheme [6]. If the level sequence is $0<1<2$, the fit procedure yields $\Delta E=90 \pm 4 \mathrm{~cm}^{-1}$, $\tau_{1}=2215 \pm 25 \mu \mathrm{s}$ and $\tau_{2}=600 \pm 250 \mathrm{~ns}$. Here $\Delta E$ is

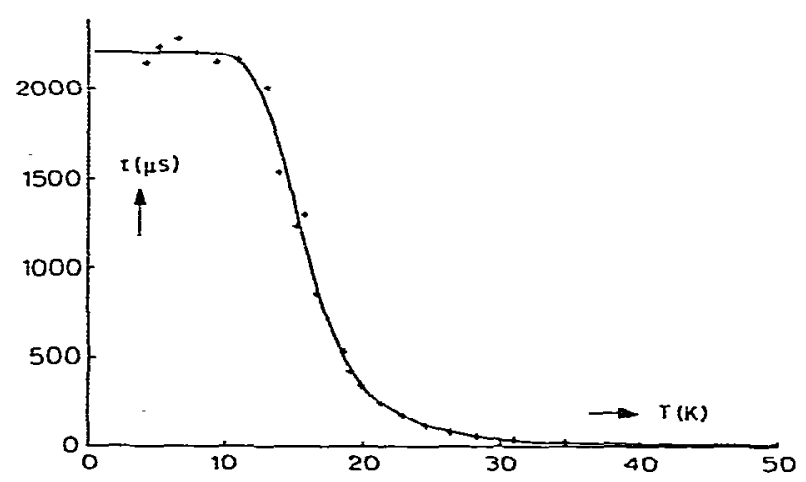

Fig. 1. Decay times of the emission of $\mathrm{Rb}_{2} \mathrm{TeBr}_{6}$ as a function of temperature. Excitation wavelength $380 \mathrm{~nm}$, enission wavelength $680 \mathrm{~nm}$. 
the energy difference between levels 1 and 2 , and $\tau_{i}$ the purely radiative decay time of level $i$.

The same luminescence was observed for isomorphous $\mathrm{Rb}_{2} \mathrm{SnBr}_{6}$ : Te. The emission band was slightly shifted to higher energy as observed also for the analogous cesium compounds [5]. This shows that the luminescence is due to the $\mathrm{TeBr}_{6}-$ octahedron.

An analysis of the present observations in terms of the $5 \mathrm{~s}^{2}$ configuration of $\mathrm{Te}^{4+}$ is obvious. Stufkens [7] has reported the absorption spectrum of $\left(\mathrm{Bu}_{4} \mathrm{~N}\right)_{2} \mathrm{TeBr}_{6}$ in $\mathrm{CH}_{2} \mathrm{Cl}_{2}$ and found the $\mathrm{A}$ band $\left({ }^{1} \mathrm{~S}_{0}-{ }^{3} \mathrm{P}_{1}\right)$ at about $460 \mathrm{~nm}$ and the $C$ band $\left({ }^{1} S_{0}-{ }^{1} P_{1}\right)$ at about $330 \mathrm{~nm}$. In $\mathrm{Rb}_{2} \mathrm{TeBr}_{6}$ we find these transitions at 485 and 350 $\mathrm{nm}$. The asymmetry observed in the $A$ excitation band is ascribed to the dynamical Jahn-Teller effect $[2,7]$.

The emission is due to the ${ }^{3} \mathrm{P}_{1,0} \rightarrow{ }^{1} \mathrm{~S}_{0}$ transition, i.e. level 0 in the three-level scheme is the ground state ${ }^{1} \mathrm{~S}_{0}$, level 1 is ${ }^{3} \mathrm{P}_{0}$, level 2 is ${ }^{3} \mathrm{P}_{1}$. The energy difference ${ }^{3} \mathrm{P}_{1}-{ }^{3} \mathrm{P}_{0}$ is $90 \mathrm{~cm}^{-1}$. At liquid-helium temperature the emission is from ${ }^{3} \mathrm{P}_{0}$ as shown by the long decay time (2.2 ms) resulting from the $J=0 \rightarrow J=0$ selection rule. Above $10 \mathrm{~K}$ the ${ }^{3} \mathrm{P}_{1}$ level is also occupied and the decay time decreases. The value of $\tau_{2}(\approx 0.6 \mu \mathrm{s})$ reflects the spin selection rule.

One observation does not fit in this general scheme, viz. the presence of a strong band in the excitation spectrum between the $A$ and the $C$ band. It is far too itrong to be assigned to the $B$ band which was observed ay Stufkens as a weak shoulder. We ascribe this band to the $D$ band [2], i.e. to a charge-transfer transition from the $\mathrm{Br}^{-}$ions to the central $\mathrm{Te}^{4+}$ ion.

For the lower-charged mercury-like ions the $D$ band is usually found at energies higher than that of the $\mathrm{C}$ band [2]. However, the high positive charge of the $\mathrm{Te}^{4+}$ ion will shift the $D$ band to lower energies. A similar observation has been made before for $\mathrm{Bi}^{3+}$ in bromides [8].

Finally we note that energy migration among the $\mathrm{TeBr}_{6}^{2-}$ octahedra is not possible in view of the considerable Stokes shift [9]. As a consequence no concentration quenching of the luminescence is observed.

In conclusion we have characterized the luminescence of one of the higher charged mercury-like ions, viz. $\mathrm{Te}^{4+}\left(5 \mathrm{~s}^{2}\right)$.

\section{References}

[1] P. Goldberg, ed., Luminescence of inorganic solids (Academic Press, New York, 1966) chs. 2, 5.

[2] A. Ranfagni, D. Mfugnaĩ, M, Bacci, G. Viliani and M.P. Fontana, Advan. Phys. 32 (1983) 823.

[3] W. Abriel and J. Ihringer, J. Solid State Chem. 52 (1984) 274.

[4] C.W.M. Timmermans and G. Blasse, J. Solid State Chem. 52 (1984) 222.

[5] J.F. Ackerman, Mater. Res. Bull. 19 (1984) 783.

[6] B. DiBartolo, Optical interactions in solids (Wiley, New York, 1968) ch. 18.

[7] D.J. Stufkens, Rec. Trav. Chim. Pays-Bas 89 (1970) - 1185.

[8] C.W.M. Timmermans and G. Blasse, Phys. Stat. Sol $118 b$ (1983) 353;

A. Wolfert and G. Blasse, Phys. Stat. Sol. b, to be published.

[9] R.C. Powell and G. Blasse, Struct. Bonding 42 (1980) 43. 